\title{
Husserl: Teoria do sentido e comunicação
}

Pedro M. S. Alves

I. O programa fenomenológico de Edmund Husserl assenta numa ideia-força de fácil compreensão. Trata-se de regredir sistematicamente dos objectos oferecidos à teorização científica até às formas como esses objectos são dados a uma consciência e podem ser apreendidos enquanto tais. No quadro da fenomenologia, não se trata de discutir, em termos ontológicos, o que é, por exemplo, um número, um objecto do mundo natural, uma obra de arte, etc., mas de explicitar as formas como nos podem ser dadas coisas tais, isto é, o sentido dos actos de consciência em que coisas como números, objectos naturais ou obras de arte podem ser experienciadas e reconhecidas no seu teor próprio de sentido.

Este programa de pesquisa pode ser estendido a qualquer tipo de objectividade. Na sua formulação geral, o problema fundamental da fenomenologia cifra-se, por isso mesmo, na seguinte interrogação: como pode em geral haver algo como um mundo para a consciência, como se efectiva e em que consiste a experiência em que o mundo se depara e se torna presente? De acordo com esta orientação de base, a fenomenologia apresenta-se como uma teoria das teorias ou como uma ciência fundamental. De facto, a questão que a ocupa não versa sobre a explicação cientifica de uma qualquer realidade positiva, mas diz antes respeito à descrição da génese do sentido pela qual qualquer realidade se torna presente e disponivel para uma consciência e, ulteriormente, para o saber cientifico-positivo correspondente. Esta orientação da fenomenologia, em que se produz uma regressão sistemática do mundo objectivo dado até às condições que tornam possivel uma experiência de mundo, faz dela, na caracterização do próprio Husserl, uma filosofia transcendental.

II. No quadro de uma fenomenologia do espaço comunicacional, a questão primeira será então a seguinte: qual o teor de sentido da experiência em que o fenómeno comunicativo se efectiva, como e quando dizemos que estamos perante um fenómeno de comunicação? O fenómeno da comunicação tem como condições necessárias a doação, em fundo, de uma "simples natureza" de coisas na espácio-temporalidade objectiva e de uma multiplicidade de sujeitos nas formas concretas da sua existência corpórea, anímica e socializada.

No entanto, a simples apreensão de um outro homem sob o pano de fundo do mundo cousal e dos objectos sociais a que as formas da socialização se referem não é ainda condição suficiente para a emergência do fenómeno da comunicação. De facto, mesmo a apreensão de um outro homem pode reduzi-lo a um ser puramente corpóreo e natural que funciona como substrato de uma natureza anímica ou psíquica. Vemos a dor de outrem no esgar do rosto que observamos, a pressa, no ritmo dos passos, etc. Em todos esses casos, há efectivamente apreensão de um 
outro homem, mas ele é apenas um corpo do meu mundo em que se vêm expressar certos fenómenos psíquicos que apreendo ainda como objectos para mim. Nesse caso, outrem é, aí, ainda um puro e simples objecto do meu mundo circundante. Mesmo quando os caracteres da experiência prática e axiológica o vêm sobredeterminar, não há ainda aí um autêntico fenómeno de comunicação. O mesmo homem que vejo diante de mim e que continuo a observar pode certamente produzir efeitos sobre a minha subjectividade que já não são simples influxos físico-naturais. Pode despertar reacções de agrado ou desagrado, de prazer ou desprazer, pode ser valorado como atractivo ou repugnante, sem que, no entanto, com estes caracteres práticos e axiológicos, ele seja outra coisa mais que um simples objecto do meu mundo circundante relativamente ao qual se verifica um comportamento meu, mas com o qual não há ainda efectiva comunicação. De facto, a comunicação tem lugar quando o "em-face" dos objectos cede o seu lugar ao "face-a-face" dos sujeitos. Um objecto, apreendemo-lo, mesmo que esse objecto seja mais que uma realidade puramente corporal. Contudo, só perante outro sujeito nos exprimimos e comunicamos.

Numa passagem das Ideias II, no §51, Husserl faz uma penetrante descrição da estrutura de sentido da intenção comunicativa. O texto reza assim:

Há precisamente ainda uma outra forma de acção das pessoas sobre as pessoas: elas orientam-se umas para as outras na sua acção espiritual (o ego próprio para outrem e inversamente), elas consumam actos com o propósito de serem compreendidas por aquele que lhes faz face e de o determinar, através da sua apreensão compreensiva de tais actos (exteriorizados com esse propósito), a certos modos de comportamento pessoais. [...] Deste modo, formam-se relações de acordo: ao discurso segue-se a resposta, à pretensão de ordem teórica, valorativa, prática, que um endossa ao outro, segue-se, por assim dizer, o retorno respondente, a concordância (o consentimento) ou a recusa (a dissensão), eventualmente uma contra-proposta, etc. Nestas relações de acordo produz-se uma relação de reciprocidade consciente das pessoas e, ao mesmo tempo, uma relação unitária das mesmas a um mundo circundante comum'.

Com a sua habitual genialidade analítica, Husserl capta aqui de uma forma excelente a complexidade da intenção comunicativa. Ela é a síntese de três momentos diferenciados. Nela há

(1) um endossamento a outrem, suportado pela manifestação de uma intenção cooperativa (o dirigir a palavra a alguém);

1 «Es gibt eben noch eine andere Form des Wirkens von Personen auf Personen: sie richten sich in ihrem geistigen Tun aufeinander (das Ich auf den Anderen und umgekehrt), sie vollziehen Akte in der Absicht, von ihrem Gegenüber verstanden zu werden und es in seinem verstehenden Erfassen dieser Akte (als in solcher Absicht geäusserter) zu gewissen persönlichen Verhaltungsweisen zu bestimmen. [...] Es bilden sich so Beziehungen des Einverständnisses: auf der Rede folgt Antwort, auf die theoretische, wertende, praktische Zumutung, die der Eine dem Anderen macht, folgt die gleichsam antwortende Rückwendung, die Zustimmung (das Einverstanden) oder Ablehnung (das Nicht-einverstanden), ev. ein Gegenvorschlag usw. In diesen Beziehungen des Einverständnisses ist eine bewusstseinsmässige Wechselbeziehung der Personen und zugleich eine einheitliche Beziehung derselben zur gemeinsamen Umwelt hergestellt». Husserl, Ideen II, Hua IV, pp. 192-193. 
(2) um conteúdo proposicional que, segundo os casos, dá a base para um acto de asserção, de expressão de um desejo, de uma interrogação, etc. (trata-se daquilo que está dito no acto de fala);

(3) a expectativa de uma acção, em sentido lato, por parte do interlocutor, não só como correspondimento à intenção cooperativa, mas como estando motivada por ela (o acto de fala suscita, do lado do interlocutor, o seu complemento respondente, que é o preenchimento da intenção comunicativa do locutor);

Assim, no jogo das relações de reciprocidade do interpelar e responder, desenha-se finalmente um espaço de concordância (Einverständnis), entre actos comunicativos e suas respostas, em que se forma e sedimenta um saber partilhado que é o lugar de constituição de um mundo comum.

O fenómeno da comunicação é a interacção entre pessoas no mútuo reconhecimento de uma influência recíproca. Ele só ocorre quando o outro deixa de ser objecto do meu mundo circundante e irrompe como outro sujeito que não está apenas diante de mim, mas que está comigo numa interacção pela qual em conjunto nos referimos a um mundo comum. Como Husserl observa logo de seguida, "o mundo circundante que se constitui na nossa experiência dos outros, na compreensão recíproca e no acordo, é o mundo comunicativo» ${ }^{2}$. O mundo da comunicativo não é, assim, mundo "para mim" ou para outrem, mas precisamente mundo partilhado ou mundo "para todos nós". Ele supõe a experiência intersubjectiva, o mútuo reconhecimento e a referência conjunta a um mundo comum de objectividades naturais e sociais.

No quadro de uma fenomenologia do espaço comunicacional e a fim de surpreender este aparecimento originário do outro não como objecto do meu mundo, mas como co-sujeito de um mundo comum, o elemento capital é a linguagem. De facto, outrem não me aparece originariamente enquanto tal pelo facto de me transformar de sujeito do meu mundo em objecto do seu mundo e de essa transformação ocorrer para a minha consciência. A dialéctica do regard d'autrui, bem analisada por Sartre, não é ainda o lugar de constituição da relação comunicativa. Ela é, como o próprio Sartre o mostra, apenas o momento em que «eu não sou para mim senão como reenvio para outrem $»^{3}$ - pura evasão do meu mundo e consciência de mim sob a forma do devir-objecto para um outro. Outrem surge para mim, porém, não como aquele que me reduz a objecto do seu mundo circundante, mas antes como a instância que transforma a consciência de um "eu" na consciência de um "nós", e a presença de um mundo "meu" na presença de um mundo comum. Esta entrada do outro na minha experiência não é, portanto, o momento da minha redução a objecto para uma consciência alheia, mas o aparecimento de um outro sujeito que comigo comunica na medida em que para mim se exterioriza e eu próprio para ele me exteriorizo numa relação de mútuo endossamento e de mútua compreensão. O elemento decisivo para esta comunicação é justamente a linguagem, porque só por ela alguém me surge como estando em comunicação comigo por referência a um mundo que, nessa comunicação mesma, para nós fica constituído como mundo comum. Por isso, é na linguagem que um

2 «Die sich im Erfahren von den Anderen, im Wechselverständnis und im Einverständnis konstituierende Umwelt bezeichnen wir als kommunikative». Husserl, Ideen II, Hua IV, p. 193.

3 Sartre - L'être et le néant: Essai d'ontologie phénoménologique. Paris: Gallimard, 1943, p. 307. 
outro sujeito originariamente se anuncia e se dá a ver. Ela é, assim, o primeiro rosto de outrem na relação comunicativa.

III. Na sua primeira grande obra, as Investigações Lógicas, de 1901, Husserl desenvolve, logo na primeira investigação, uma teoria fenomenológica da linguagem. A análise de Husserl é governada por uma série de pressupostos organizadores. Nomeadamente,

(1) que nem os sinais, falados ou escritos, nem a manifestação (Kundgebung) da subjectividade daquele que se exprime são essenciais para a caracterização da essência da linguagem;

(2) que o elemento essencial da linguagem é a expressão de um sentido ou significação, seja essa expressão realizada numa linguagem ou noutra, seja em signos escritos ou em palavras, seja mesmo quando tal mediação de um signo material desaparece quase completamente no monólogo interior (im einsamen Seelenleben);

(3) que este sentido é sempre acerca de uma qualquer coisa que através dele se torna consciente como o objecto acerca de que se fala.

Esta teoria da linguagem conecta-se com a teoria husserliana da intencionalidade da consciência. Na bem conhecida afirmação programática de Husserl, toda e qualquer consciência é sempre consciência de qualquer coisa. A teoria fenomenológica da linguagem permite mostrar que este acto de visar algo é o lugar onde se insere a significação de um enunciado e que, através dessa significação, qualquer coisa é visada segundo uma forma particular de sentido.

O modo como, nesta primeira fase das Investigações, Husserl compreende a significação afasta, porém, a sua teoria da linguagem de uma autêntica fenomenologia do espaço comunicacional ${ }^{4}$. De facto, toda a teoria husserliana da linguagem está trabalhada pela ideia directora da unidade e da idealidade da significação, uma tese directamente vinculada às posições de Frege sobre o Sinn de um enunciado e à teoria bolzaniana do Satz an sich. Esta tese segundo a qual a significação de um enunciado é ideal deve ser bem compreendida, pois ela é o elemento capital da posição husserliana. Uma analogia pode ser útil. Por exemplo, no caso do jogo de xadrez, podemos dizer que, uma vez definidas as regras de movimento para cada peça, todas as jogadas e todos os jogos possíveis ficam também definidos. Cada jogada, ou cada jogo completo, é apenas a realização de uma parcela muito limitada do universo de possibilidades total. Este conjunto das possibilidades permite dizer, em certo sentido, que todas as partidas concretas de xadrez estão já pré-definidas de antemão. A pré-existência do conjunto de todos os possíveis não é nenhuma jogada, nenhuma partida em particular, nem sequer o conjunto de todas as partidas reais. Tem antes uma existência de outra ordem. Não uma existência real, no espaço e no tempo, mas justamente uma existência ideal, enquanto esfera fechada da combinatória de todos os lances possiveis que delimita de antemão todas as formas concretas realizáveis. Do mesmo modo para a tese da idealidade da significação, a combinatória de todos os elementos da significação segundo as regras formais e materiais de uma gramática pura das significações e de uma ontologia material, produzirá o conjunto ideal de todos os enunciados linguísticos possíveis que tenham sentido, dos quais uns serão verdadeiros para

4 Para uma distinção entre "duas fases" da compreensão husserliana da essência da linguagem, veja-se o estudo clássico de Maurice Merleau-Ponty "Sur la phénoménologie du langage", primeiramente publicado em Problèmes actuels de la phénoménologie (Bruxelles, 1952), e, mais tarde, em Signes (Paris, Gallimard, 1960). 
um certo mundo de experiência factual, outros verdadeiros em todos os mundos possíveis, outros ainda falsos em todos eles, etc.

Neste contexto, a significação de um enunciado, porque ideal, aparece como um invariável que pode ser sempre retomado em actos diferentes de expressão pertencendo a múltiplos sujeitos e situados em contextos diferenciados. Ela atravessa assim, como uma invariante, a diversidade dos sujeitos, das culturas e das épocas históricas. Esta tese da idealidade da significação tem toda a plausibilidade em certas esferas, nomeadamente as do pensamento lógico e matemático em sentido lato, as quais são as áreas em que Husserl efectivamente começou por trabalhar. De acordo com esta visão da essência da linguagem, torna-se possivel compreender a razão por que o enunciado que exprime, por exemplo, o Teorema de Pitágoras conserva um teor de sentido idêntico e-imutável, seja ele enunciado em grego, em francês ou português, seja ele compreendido por sujeitos de uma ou outra cultura ou pertencentes a épocas históricas diferentes. Tal é o resultado desta anterioridade da significação, ideal e idêntica, em relação ao acto concreto da linguagem expressiva e ao seu contexto psicológico, histórico e cultural.

No entanto, esta compreensão do primeiro Husserl acerca da essência da linguagem não pode dar conta do acto comunicativo em sentido estrito. Ela estabelece

(1) o modo como se partilha um sentido sempre idêntico através de um medium, que pode ser uma linguagem natural, um conjunto de sinais ou mesmo de gestos, desde que estes não valham simplesmente como tais, na sua pura materialidade, mas justamente enquanto portadores de significação;

(2) nessa transmissão ou partilha do mesmo sentido não se atende nem ao emissor nem ao receptor - a informação está lá, na sua positividade, objectivamente, e pode ser apropriada por qualquer um que tenha acesso ao código de decifração;

(3) por força do carácter referencial da significação ideal, o sentido volve-se em informação acerca de qualquer coisa ou qualquer facto de um mundo real ou possível - ele versa sempre sobre qualquer coisa, sem que, para a compreensão do seu sentido, interesse aqui a subjectividade daquele que se exprime e daquele que compreende, mas apenas a verdade ou falsidade daquilo que está dito no enunciado.

O sentido, assim volvido em informação acerca de um mundo, efectivo ou possível, apaga o seu emissor, encobre-o na positividade do que está dito $e a$ regressão do sentido expresso até à subjectividade daquele que se exprime não é um elemento relevante para a sua apreensão. O que está dito é verdadeiro ou falso acerca do mundo a que a linguagem se refere. Na teoria da linguagem de Husserl, vamos, assim, da significação ideal até à sua instanciação num acto concreto de fala, e, deste, até ao mundo acerca do qual ela versa e acerca do qual produz uma informação verdadeira ou falsa. A percepção de uma outra subjectividade apaga-se completamente do horizonte. Ela não é um elemento essencial neste processo de efectivação, transmissão e reapropriação do sentido.

Outra coisa se passa no fenómeno da comunicação. A comunicação investe

(1) Uma relação de mútuo reconhecimento e apresentação entre um emissor e um receptor - o medium aí operante, a linguagem ou outro qualquer, não é nunca um elemento positivo, que se baste a si próprio, mas apenas um momento mediador e uma via de acesso a outrem no quadro de uma relação intersubjectiva;

(2) A direcção da intenção comunicativa não vai do conteúdo informativo de uma mensagem até às coisas de que se fala, mas regride antes desse conteúdo, entendido não como informação mas como expressão, até à apreensão daquele que o produz, e é essa a forma relevante de apropriação do conteúdo de sentido no horizonte da relação comunicativa. 
(3) Na relação comunicativa, as facticidades que formam o contexto psicológico e cultural nunca são um elemento irrelevante; pelo contrário, são elas que fornecem o horizonte em que se efectiva a apreensão de outrem enquanto sujeito que se põe com outrem numa relação de comunicação.

$\mathrm{Na}$ medida em que interdita esta última passagem, a teoria husserliana da linguagem exposta na primeira investigação permanece ainda aquém de uma autêntica fenomenologia do espaço comunicacional.

IV. Uma fenomenologia da intenção comunicativa deveria recuperar, neste ponto, alguns resultados da pragmática, nomeadamente a distinção entre conteúdo proposicional e força ilocutória ${ }^{5}$, bem como as análises percursoras de Grice a respeito da estrutura da relação comunicativa ${ }^{6}$. Mas é a teoria semântica, proveniente da análise lógica da linguagem, que permite contornar este obstáculo da teoria husserliana da linguagem através da distinção entre contextos intensionais e extensionais e, mais precisamente, através do tratamento dos chamados verbos-de-acção. Um enunciado intensional é um enunciado cujo valor de verdade não fica determinado pelas extensões dos seus elementos semanticamente significantes. Todos os enunciados intensionais têm a particularidade de não permitirem a substituição de expressões co-referenciais, mantendo o mesmo valor de verdade, e de não permitirem também a generalização existencial. Dentro dos enunciados intensionais, são relevantes para o nosso propósito os que modificam as proposições pela anteposição de operadores de acto. A proposição "a alma de Sócrates é imortal" torna disponível uma informação, verdadeira ou falsa, sobre um suposto facto do mundo. Ela declara que é o caso de Sócrates ter uma alma e de essa alma ser imortal. Mas as proposições "Platão crê que a alma de Sócrates é imortal" e "Platão deseja que a alma de Sócrates seja imortal" expressam não um facto sobre o mundo, mas uma crença e um desejo de um sujeito particular, a saber, Platão, uma crença e um desejo que são independentes de haver objectivamente algo como almas que possam verificar ou não o predicado da imortalidade. Numa palavra, os contextos intensionais obtidos por operadores de acção modificam o teor declarativo dos enunciados e exprimem atitudes subjectivas, em lugar de factos objectivos do mundo sobre o qual esses enunciados versam. Em vez de descreverem o mundo na sua objectividade, eles manifestam crenças, desejos, expectativas, etc., e fazem emergir, por essa via, uma forma de organização dos enunciados que já não se apoia no que é objectivamente verificável acerca do mundo, mas antes no modo como as crenças entre si se organizam, se pressupõem e implicam umas às outras, se excluem mutuamente, permitem atitudes optativas sobre elas fundadas e, na sua globalidade, se referem a um mundo já recoberto pelos modos culturais da sua apreensão. Numa palavra, a modificação sistemática dos enunciados extensionais pela forma " $X$ crê, deseja, espera, etc." faz recuar para segundo plano a linguagem informativa e o mundo a que ela se refere, para fazer emergir o espaço da inter-subjectividade e a referência a um mundo já atravessado pela densidade das formações culturais.

5 Na esteira da obra pioneira de Austin, How to do Things with Words (Oxford, 1962), a formulação clássica é a de Searle, em Speech Acts. Cambridge, Cambridge University Press, 1969, pp. 23-24.

6 Veja-se Paul Grice, “Meaning”, Philosophical Review 1957(66), pp. 377-388. 
V. Husserl recupera à sua maneira esta dimensão na sua teoria das chamadas "atitudes dóxicas". Mas, para uma fenomenologia do espaço comunicacional, há que ultapassar os problemas lógicos e semânticos levantados pelos contextos intensionais e regredir até ao elemento que surge aqui como decisivo - justamente o facto de a compreensão de um enunciado não ser agora a apreensão do seu conteúdo declarativo e dos factos do mundo que ele descreve, mas esse movimento inverso de regressão do conteúdo do enunciado até à subjectividade daquele que se exprime. A questão decisiva é, aqui, por conseguinte, a apreensão de outrem, a apreensão de um outro sujeito, e a comunicação aí estabelecida no quadro mais lato de uma teoria do mundo intersubjectivo. Tomada nesta nova orientação, não temos, de um lado, o mundo, ou aquilo que é objectivamente verificável e, do outro lado, a linguagem declarativa que o descreve de um modo impessoal. $\mathrm{O}$ mundo aparece neste contexto sempre como mundo representado por alguém, e este "alguém" que o representa pode ser certamente apenas um sujeito individual, mas um tal sujeito pode ser também toda uma cultura ou uma época histórica determinada. Só a fenomenologia da intersubjectividade, na medida em que torna por vez primeira visível este espaço intersubjectivo da mútua compreensão e da referência conjunta a um mundo que por essa via se constitui como comum, pode dar a base onde é possível edificar uma autêntica fenomenologia do acto comunicacional.

VI. No quadro de uma teoria da intersubjectividade, o elemento decisivo é a fenomenologia das objectividades culturais (Kulturgegenständlichkeiten). Segundo Husserl, um objecto cultural é aquele cuja apreensão remete para um mundo espiritual como lugar da sua génese. Um facto puramente natural basta-se a si próprio na sua positividade. Quanto muito, reenviará para um outro facto natural segundo uma conexão causal. Mas, por exemplo, a apreensão de uma obra de arte, de uma composição musical, ou de objectos tão vulgares como livros, mesas, copos, etc., não é a apreensão de simples corpos naturais, mas de coisas onde a densidade de uma cultura humana se vem, por assim dizer, exprimir e cristalizar. Esta remissão do objecto para um mundo espiritual, enquanto lugar de onde ele retira o seu sentido, é a característica de fundo dos objectos culturais. $\mathrm{Na}$ verdade, se esta capa de sentido lhes for retirada, ficará simplesmente a pura materialidade de um objecto corpóreo, mas o que faz desse objecto corpóreo um livro, um quadro, uma obra musical ou um acto de fala, desaparecerá completamente do horizonte.

No objecto cultural apresenta-se o mundo humano que está na sua origem. Ele tem imediatamente uma dimensão expressiva. É esse o traço fenomenológico que essencialmente o caracteriza. Num texto de Experiência e Juizo, Husserl descreve do seguinte modo a constituição de sentido destas objectividades: «O Fausto de Goethe encontra-se numa multiplicidade de livros reais [...], os quais são denominados exemplares do Fausto. Este sentido espiritual que determina a obra de arte, a formação espiritual enquanto tal, está certamente incorporada no mundo real, mas ela não está individualizada por meio da incorporação» ${ }^{7}$, porque diferentes livros em diferentes línguas e em diferentes suportes podem ser materializações dessa mesma obra, a qual permanece como algo idêntico e imutável, seja qual for a forma concreta da sua apresentação real.

7 "Goethes Faust kommt in beliebig vielen realen Büchern [...] vor, die Exemplare des Faust heissen. Dieser geistige Sinn, der das Kunstwerk, das geistige Gebilde als solches bestimmt, ist zwar in den realen Welt "verkörpert", aber durch die Verkörperung nicht individuiert». Husserl - Erfahrung und Urteil. Hamburg: Felix Meiner Verlag, 1972, §65, pp. 319-320. 
Na sua tematização deste tipo muito peculiar de objectividades, Husserl permanece ainda fascinado pela sua tese directora da idealidade do sentido. Do mesmo modo que o sentido de uma proposição permanece idêntico, seja ela dita ou escrita, seja ela proferida numa língua ou noutra, seja ela efectivamente enunciada ou apenas mentalmente representada, também o objecto cultural é um "ideal" relativamente às múltiplas formas da sua apresentação concreta. O fenómeno da repetibilidade é, aqui, o elemento crucial para a afirmação da idealidade.

Mas esta análise entreabre já as portas de acesso ao elemento verdadeiramente crucial para a edificação de uma fenomenologia do espaço comunicacional.

Primeiro, porque, como aliás o próprio Husserl reconhece, se o objecto cultural é uma idealidade, ele não é uma idealidade pura do tipo dos sistemas lógico-matemáticos, mas uma idealidade que só na medida em que se materializa no mundo real pode ser dita existir verdadeiramente. Um sistema axiomático de proposições geométricas pode ser dito existir idealmente em si, mesmo que nenhuma obra humana de geometria o descubra totalmente. Mas, ao contrário, um objecto cultural, como o Fausto de Goethe, só na medida em que é efectivamente criado e incorporado no mundo real sob a forma de uma obra pode existir no verdadeiro sentido da palavra para ser depois submetido ao processo de idealização. Uma verdade é descoberta, e ela pré-existe já a esse acto que por vez primeira a expressa. Mas os objectos culturais não são descobertos, são criados. A sua existência nunca precede a sua expressão.

Segundo, a criação de um objecto cultural é o lugar de expressão de um sistema de crenças que organiza uma representação do mundo e da vida. Olhemos, por exemplo, para uma gruta com as suas pinturas rupestres, os restos de uma fogueira há muito extinta, os artefactos do quotidiano em seu redor e todá uma profusão de objectos ornamentais e de culto. Nesta cena vazia, na medida em que a apreendemos no seu sentido como expressão de uma cultura, saltamos imediatamente para o mundo humano que aí se exprime, vemos de novo os homens de antanho, não na sua individualidade, mas como um sistema de formações espirituais que os organiza numa cultura determinada por um modo de vida, um conjunto de convicções sobre o mundo, uma forma de organização social, etc. Os objectos culturais, na medida em que se incorporam no mundo, abrem deste modo o espaço para um movimento de percepção de um sentido que ultrapassa a dimensão puramente física e natural e abre as portas para a relação intersubjectiva. É nela que a comunicação, mesmo que indirecta e mediada, como é aqui o caso, tem verdadeiramente lugar.

Terceiro, esta apropriação de sentido não é nunca unilateral. Pois não se trata aqui de uma compreensão neutra de um sentido fixo e invariável, mas de um movimento de apropriação a partir do background de crenças e da representação do mundo daquele que interpreta. Este processo está determinado por essa circunstância essencial de a mútua compreensão nunca ser um exercício de apreensão transparente de um sentido imutável, ideal e sempre idêntico, mas uma apropriação que o transporta para o nosso próprio mundo cultural e o reinterpreta no próprio acto de comunicação.

Esta nota da compreensão é evidente em certos casos-limite. De um texto como o Rei Édipo, de Sófocles, podemos dizer, na esteira de Husserl, que ele é uma idealidade que permanece sempre idêntica a si mesma, seja qual for a cultura que o lê, seja qual for a língua em que ele é vertido, seja qual for a época histórica que o introduz no seu mundo e dele se apropria. Mas isto é esquecer que, nessa repetição do mesmo, esse mesmo é sempre de novo diferente, porque a comunicação não se faz pelo comungar de um sentido ideal sempre idêntico, mas pelo movimento de 
interpretação que vai da materialidade do texto até à subjectividade do seu autor e, desta, mais atrás ainda, até à exibição do mundo cultural que aí se exprime para dele se apropriar na medida em que o incorpora no seu próprio mundo e o reinterpreta segundo o seu sistema de crenças. Se, na primeira visão de Husserl, o contexto psicológico, histórico e social do acto expressivo é inessencial para a significação, agora esse mesmo contexto surge como um pressuposto de todo o acto comunicativo. É aí que desponta o fenómeno da comunicação. Ele repercute-se por todas as formas de expressão: das obras de arte, aos textos literários, às formas da vida social e à linguagem. $\mathrm{O}$ que essencialmente o caracteriza é a passagem da dimensão significativa à expressiva.

Este "resíduo" que assim desponta no acto da comunicação, na medida em que esta está determinada não pela idealidade do sentido mas pelo jogo da interpretação, não é, no entanto, um qualquer obstáculo à mútua compreensão. Pelo contrário, nele toma forma o que é a nota essencial da comunicação - precisamente o dar-se a conhecer recíproco de sujeitos diferentes, em vez da simples transferência de um conteúdo imutável de pensamento. Assim, um tal "resíduo" constitui não um encobrimento, mas um enriquecimento do sentido que se faz no próprio acto da comunicação, na medida em que comunicar não é simplesmente declarar impessoalmente um facto sobre o mundo, mas dar-se a conhecer num exercício apontado ao objectivo final de uma mútua compreensão.

Tornar patente estes processos será, assim, introduzir uma teoria da comunicação que dê conta deste jogo de mútua contaminação e fecundação do sentido. Uma fenomenologia do acto comunicacional deverá encetar o estudo destes processos, até hoje descurados no quadro da teoria fenomenológica de inspiração husserliana. 
